\title{
The Knowledge of Sleep Medicine among Dental Interns in Northern Jordan
}

\author{
Mustafa Alkhader ${ }^{1} \quad$ Rami Saadeh $^{2}$ \\ ${ }^{1}$ Department of Oral Medicine and Oral Surgery, Faculty of \\ Dentistry, Jordan University of Science and Technology, Irbid, \\ Jordan \\ 2Department of Community Medicine, Public Health and Family \\ Medicine, Faculty of Medicine, Jordan University of Science and \\ Technology, Irbid, Jordan
}

\begin{abstract}
Address for correspondence Mustafa Alkhader, BDS, PhD, JBOMR, Department of Oral Medicine and Oral Surgery, Faculty of Dentistry, Jordan University of Science and Technology, Irbid 22110, Jordan (e-mail: mmalkhader@just.edu.jo).
\end{abstract}

\begin{abstract}
Keywords

- sleep medicine knowledge

- dental interns

- ASKME questionnaire
\end{abstract}

Objectives The diagnosis and treatment of patients with sleep disorders are the most challenging issues in dentistry. The aim of this study was to assess the knowledge among dental interns in Northern Jordan about sleep medicine and sleep disorders.

Materials and Methods This cross-sectional study was performed using the Assessment of Sleep Knowledge in Medical Education (ASKME) questionnaire. The questionnaire was given to 88 dental interns (52 females and 36 males) in Northern Jordan. Chi-squared test was utilized for data analysis.

Results The mean score of the ASKME questionnaire was 12 out of $30(40 \%)$. The majority of dental interns (88.6\%) correctly answered $\leq 50 \%$ of the questions. No association was found between gender and score results.

Conclusions Dental interns in Northern Jordan have a low level of knowledge about sleep medicine and sleep disorders. Dental faculties should provide courses related to sleep medicine throughout undergraduate education.

\section{Introduction}

The high prevalence of sleep disorders that affects all age groups has led to an abundant use of sleep medication. ${ }^{1}$ There are over 80 different sleep disorders classified by the International Classification of Sleep Disorders-3 (ICSD-3), which can be diagnosed and treated effectively. ${ }^{2}$ These sleep disorders vary in their effect on the human body, usually resulting in lower quality of life, morbidities, and even mortality. For example, obstructive sleep apnea (OSA), which is a common sleep problem affecting $4 \%$ of middle-aged males, has been associated with several serious medical comorbidities such as hypertension, coronary artery disease, stroke, and diabetes. ${ }^{1}$ Training and education in the field of sleep medicine are crucial, as conditions such as sleep apnea can be life threatening, if left undiagnosed. ${ }^{2}$

published online October 15, 2020
DOI https://doi.org/ 10.1055/s-0040-1717154 ISSN 1305-7456.
Sleep disorders are common among the Jordanian population. Khassawneh et al reported that the risk of sleep apnea is $\sim 16.8 \%$ among Jordanians attending primary care clinics, and patients at risk should be referred for further evaluation ${ }^{3}$

In Jordan, there are two state-supported universities that serve as a platform to obtain the Bachelor Degree of Dentistry (BDS), namely "Jordan University" in Amman and "Jordan University of Science and Technology" in Irbid. The certificate is awarded upon the successful completion of 3 theoretical years and 2 clinical years, along with a 1-year internship to legally practice dentistry in Jordan. Knowing that sleep disorders have a significant impact on the health and well-being of society, it is unfortunate that these topics are not addressed in the curriculum during the first 2 years of study, and barely taught during clinical training. Health care professionals are responsible for the overall health of their patients, regardless

(C) 2020. European Journal of Dentistry.

This is an open access article published by Thieme under the terms of the Creative Commons Attribution-NonDerivative-NonCommercial-License, permitting copying and reproduction so long as the original work is given appropriate credit. Contents may not be used for commercial purposes, or adapted, remixed, transformed or built upon. (https://creativecommons.org/licenses/by-nc-nd/4.0/)

Thieme Medical and Scientific Publishers Pvt. Ltd., A-12, 2nd Floor, Sector 2, Noida-201301 UP, India 
of specialty. They require a competent level of knowledge and skills to identify sleep disorders and refer them to the specialized entities. Dentists are among those professionals who have a frontline opportunity to identify, diagnose, and even contribute in treating such patients. ${ }^{4}$

Patients at risk of developing OSA can be identified by dentists by careful examination in dental clinics. ${ }^{4-7}$ Many oral findings and oral risk factors that have been linked with OSA include increased size of tongue, tonsils, uvula, and soft palate. ${ }^{5,8}$ Furthermore, systemic diseases associated with OSA can also result in other oral manifestations such as dental caries and periodontitis. ${ }^{9}$ Another equally important point is that the treatment of many OSA patients can be performed by dentists or dental specialists. ${ }^{8}$ The fabrication of oral appliances for mandibular advancement or performance of simple surgical procedures can result in successful treatment of OSA patients. ${ }^{8}$ These signify the importance of the knowledge of sleep medicine to dentists and dental students.

Several studies have assessed the knowledge of sleep medicine, ${ }^{1,4,10-14}$ including studies conducted in the Middle East. 1,4,12,14 According to these studies, medical students, dental students, and primary care physicians possess poor knowledge of sleep medicine. However, no study had been conducted in Jordan. Therefore, the aim of this study was to assess the level of knowledge of dental interns training in Northern Jordan about sleep medicine and sleep disorders.

\section{Materials and Methods}

\section{Study Population}

This was a cross-sectional study conducted between March and April 2019. The target population was dental interns in Northern Jordan, training in Jordan's Ministry of Health dental centers or university dental centers. The total number of participants was 88 interns (52 females and 36 males).

\section{Questionnaire}

Interns' knowledge about sleep medicine was assessed via the Assessment of Sleep Knowledge in Medical Education (ASKME) survey, which is a validated tool for the assessment of medical students' knowledge about sleep disorders. ${ }^{15}$

As English is the primary language of study for dental schools in Jordan, students did not require an Arabic translation of the questionnaire. The survey consisted of 30 questions that assess knowledge of sleep disorders in the following areas: (1) basic sleep principles, (2) circadian sleep/wake control, (3) normal sleep architecture, (4) common sleep disorders, and (5) the effects of drugs and alcohol on sleep. For each question, three choices were available in the format of "true," "false," or "I don't know." Correct answers were summed up into a percentage. A hard copy of the questionnaire was distributed to all interns and collected after a short interview. Consent to participate in the study was obtained verbally from participants. The study was conducted in accordance with the Helsinki Declaration and the institutional review board ethics of Jordan University of Science and Technology (JUST).

\section{Statistical Analysis}

Descriptive statistics were used to demonstrate the distribution of demographic information and knowledge about sleep disorders. Chi-squared test was used to compare the sleep knowledge scores between females and males. The results were considered statistically significant if $p$-value $\leq 0.05$. Statistical Package for the Social Sciences, IBM version 23 (SPSS Inc.; Chicago, Illinois, United States) software was used for data analysis.

\section{Results}

All participants were dental interns with a mean age of $23 \pm 1$ year. Females represented $59 \%$ ( 52 out of 88 ) of the sample. The mean score of correctly answered ASKME questionnaire was $12.1( \pm 4.15)$ questions out of 30 questions, which represents $40 \%$. The mean score for female interns was slightly higher than that of males (12.48 \pm 4.5 vs.11.6 \pm 3.6$)$. There was no association between gender and score results. The majority of dental interns (88.6\%) correctly answered $\leq 50 \%$ of the questions. The percentage of correct answers obtained for each question in the ASKME survey is summarized in $\boldsymbol{- T a b l e ~} \mathbf{1}$.

\section{Discussion}

The results demonstrated a limited level of knowledge about sleep medicine among Jordanian dental interns, which seems to be attributed to the deficiency of education and training provided during their dental school education. Early diagnosis of patients with sleep disorders is very important in the success of treatment and positive outcomes. ${ }^{2,15}$ The results of this study are alarming, as many of these interns will be practicing soon after the end of their internship training period. Both genders failed to correctly answer more than $50 \%$ of the questions, despite the slight difference among the two. The absence of statistical difference between both is expected, due to receiving the same curriculum during their dental education.

Similar to this study, knowledge about sleep medicine was low among medical students in selected Saudi Medical Schools, ${ }^{1}$ and the mean score of the ASKME questionnaire was $10.39 \pm 4.44$ out of 30 , which is close to the score obtained in this current study. Findings of other studies $^{4,11,13}$ also showed the low level of knowledge about sleep medicine and sleep disorders. A direct comparison with this study is not possible, since different kinds of questionnaires were used.

Contrary to the lack of gender difference in ASKME knowledge, sleep medicine knowledge among medical students in seven Egyptian medical faculties illustrated significantly higher scores of knowledge $(p=0.0180)$ for female students (12.3) compared with male students (11.7).${ }^{14}$ It is interesting, however, that our findings also showed higher knowledge scores for female students as in the Egyptian study.

In Jordan's dental education, there are no specific courses in the curriculum that discuss sleep medicine in depth. However, in postgraduate courses such as prosthodontics, students are 
Table 1 The percentage and number of correct answers for each question of the ASKME questionnaire given to dental interns

\begin{tabular}{|c|c|c|}
\hline No. & Questionnaire & $n(\%)$ \\
\hline 1 & The need for sleep decreases in persons above 50 years of age & $33(37.5)$ \\
\hline 2 & Melatonin is a natural body hormone that typically increases during nighttime hours & $42(47.7)$ \\
\hline 3 & Dream sleep (REM) occurs more during the second half of the night & $43(48.9)$ \\
\hline 4 & $\begin{array}{l}\text { Sleeping longer on the weekends is recommended as a regular practice to make up for loss of sleep during the } \\
\text { workweek }\end{array}$ & $51(58)$ \\
\hline 5 & Newborn infants spend $\sim 16-18$ hours per 24 -hour period sleeping & $75(85.2)$ \\
\hline 6 & Insomnia is twice as common in older men compared with older women & $33(37.5)$ \\
\hline 7 & $\begin{array}{l}\text { A young (preadolescent) child who regularly has trouble getting to sleep at night should be allowed to sleep } \\
\text { later in the morning }\end{array}$ & $24(27.3)$ \\
\hline 8 & The typical age of symptom onset for narcolepsy is 40 years or older & $11(12.5)$ \\
\hline 9 & The ability to sleep increases in persons above 50 years of age & $46(52.3)$ \\
\hline 10 & Slow wave sleep is more prominent during the second half of the night & $30(34.1)$ \\
\hline 11 & The amount of slow wave sleep increases in persons above 50 years of age & $17(19.3)$ \\
\hline 12 & Episodes of sleepwalking tend to occur during the last third of the night & $21(23.9)$ \\
\hline 13 & Episodes of REM sleep tend to lengthen throughout the night & $33(37.5)$ \\
\hline 14 & Periodic limb movements during sleep are typically decreased during REM sleep & $11(12.5)$ \\
\hline 15 & Hyperactivity among children can be exacerbated by inadequate sleep & $40(45.5)$ \\
\hline 16 & Among alcoholics in recovery, sleep normalizes within 1 month of alcohol abstention & $11(12.5)$ \\
\hline 17 & Daytime napping is recommended for patients with difficulty initiating sleep & $39(44.3)$ \\
\hline 18 & Weight loss is often indicated in the treatment of primary snoring or mild obstructive sleep apnea & $55(62.5)$ \\
\hline 19 & Slow wave sleep is enhanced following daytime exercise & $51(58)$ \\
\hline 20 & Chronic bed wetting among children responds to treatment with anticholinergic drugs & $26(29.5)$ \\
\hline 21 & Nightmares are more common within the first 2 hours of sleep & $41(46.6)$ \\
\hline 22 & Heart rate, respiration, and blood pressure are more variable during REM sleep compared with non-REM sleep & $37(42)$ \\
\hline 23 & Antihypertensive drugs (namely, $\beta$-blockers) may cause sleeping difficulties as a side effect & $45(51.1)$ \\
\hline 24 & $\begin{array}{l}\text { Early morning awakenings among the elderly are often associated with changes in the timing of their biological } \\
\text { rhythms }\end{array}$ & $52(59.1)$ \\
\hline 25 & Alcohol can be beneficial in reducing the effects of jet lag & $30(34.1)$ \\
\hline 26 & $\begin{array}{l}\text { Night shift workers are more likely to fall asleep on the job compared with employees with regular, daytime } \\
\text { hours }\end{array}$ & $64(72.7)$ \\
\hline 27 & Episodes of sleepwalking commonly occur during REM sleep & $18(20.5)$ \\
\hline 28 & Menopausal women are at higher risk of developing symptoms of sleep apnea than premenopausal women & $45(51.1)$ \\
\hline 29 & An irregular sleep schedule can increase the incidence of sleepwalking in children & $35(39.8)$ \\
\hline 30 & Symptoms of narcolepsy are related to seizure activity in the brain & $9(10.2)$ \\
\hline
\end{tabular}

Abbreviations: ASKME, Assessment of Sleep Knowledge in Medical Education; REM, rapid eye movement.

taught the treatment modalities for sleep apnea, specifically focusing on oral appliance therapy, in addition to limited topics about sleep medicine taught in physiology through learning the basics of sleep physiology. This signifies the low number of teaching hours in sleep medicine ( 2 hours) compared with the average total undergraduate teaching time (3.92 hours) in dental schools in Australia and New Zealand ${ }^{16}$ or ( 4.5 hours) in dental schools in the United States. ${ }^{17}$

It is obvious that sleep medicine education has a lower priority in the curriculum of dentistry in Jordan, probably because of time constraints since the dental curriculum is full of many topics that range from basic sciences to advanced clinical courses, justifying for students their lack of time to search for this topic and other similar important topics that are not included in the curriculum.

Although sleep medicine is not a main concern for dentists in general, it is still quite important for dentists to acquire enough knowledge about it because of their involvement in diagnosing and treating different sleep problems, such as OSA, sleep bruxism, and others. ${ }^{8,9}$ At the internship level, sleep medicine is not considered a core educational requirement, while other specialties, such as pediatrics, periodontics, and endodontics, are considered more important.

Possible solutions to overcome this problem include increasing the number of lectures on sleep medicine during preclinical years, incorporating basic sleep science topics into 
the curriculum of the clinical years in courses such as oral medicine and oral diagnosis, and integrating sleep history and physical signs examination into clinical examination. Almohaya et $\mathrm{al}^{1}$ proposed alternative methods to integrate sleep topics into the existing curriculum blocks. They suggested covering sleep-related material in qualifying exams, which encourage the inclusion of sleep medicine in medical education and competency-based learning. The above can be implemented in Jordan's universities, as most medical schools use the same approach.

There are limitations to this study. A larger sample size that considers different demographic information is necessary, with extended focus on practicing dentists and not only interns. In addition, because the ASKME questionnaire scale had only three options (true, false, and I don't know), authors of this study couldn't guarantee that participants were not simply guessing the answers of the questions.

\section{Conclusions}

The findings of this study indicate that sleep medicine education for dental students in Northern Jordan is inadequate. Dentists have a major role in screening, diagnosis, and management of sleep disorders. Poor knowledge in this area can have serious negative effects on the health of dental patients who remain undiagnosed when they visit their dentist. Therefore, it is essential to allocate a larger portion to teaching sleep medicine in dental school curriculums.

\section{Funding \\ None.}

\section{Conflict of Interest}

None declared.

\section{Acknowledgment}

We are thankful to fifth year dental students for their help in distributing the questionnaire, especially Dr. Jessy Salsaa and Dr. Aya Alawneh who helped in completing this study. We would also like to thank Dr Abdullah Rashdan for his efforts in proofreading and corrections/ adjustments.

\section{References}

1 Almohaya A, Qrmli A, Almagal N, et al. Sleep medicine education and knowledge among medical students in selected Saudi Medical Schools. BMC Med Educ 2013;13(1):133
2 Development of the ICSD. In: International classification of sleep disorders: Diagnostic and coding manual, 2nd edition. Westchester, IL: American Academy of Sleep Medicine; 2005:2-3

3 Khassawneh B, Ghazzawi M, Khader Y, et al. Symptoms and risk of obstructive sleep apnea in primary care patients in Jordan. Sleep Breath 2009;13(3):227-232

4 Talaat W, AlRozzi B, Kawas SA. Sleep medicine education and knowledge among undergraduate dental students in Middle East universities. Cranio 2016;34(3):163-168

5 Kurt G, Sisman C, Akin E, Akcam T. Cephalometric comparison of pharyngeal airway in snoring and non-snoring patients. Eur J Dent 2011;5(1):84-88

6 Gungor AY, Turkkahraman H, Yilmaz HH, Yariktas M. Cephalometric comparison of obstructive sleep apnea patients and healthy controls. Eur J Dent 2013;7(1):48-54

7 Gungor AY, Turkkahraman H. Effects of airway problems on maxillary growth: a review. Eur J Dent 2009;3(3):250-254

8 Petrou-Amerikanou C, Belazi MA, Daskalopoulou E, Vlachoyiannis E, Daniilidou NV, Papanayiotou PC. Oral findings in patients with obstructive sleep apnea syndrome. Quintessence Int 2005;36(4):293-298

9 Kale SS, Kakodkar P, Shetiya SH. Assessment of oral findings of dental patients who screen high and no risk for obstructive sleep apnea (OSA) reporting to a dental college - a cross sectional study. Sleep Sci 2018;11(2):112-117

10 Kovacić Z, Marendić M, Soljić M, Pecotić R, Kardum G, Dogas Z. Knowledge and attitude regarding sleep medicine of medical students and physicians in Split, Croatia. Croat Med J 2002;43(1):71-74

11 Luo M, Feng Y, Li T. Sleep medicine knowledge, attitudes, and practices among medical students in Guangzhou, China. Sleep Breath 2013;17(2):687-693

12 Saleem AH, Al Rashed FA, Alkharboush GA, et al. Primary care physicians' knowledge of sleep medicine and barriers to transfer of patients with sleep disorders. A cross-sectional study. Saudi Med J 2017;38(5):553-559

13 Sivagnanam G, Thirumalaikolundusubramanian P, Sugirda P, Rajeswari J, Namasivayam K, Gitanjali B. Study of the knowledge, beliefs, and practice of sleep among medical undergraduates of Tamilnadu, India. MedGenMed 2004;6(4):5

14 Zaki N, Marzouk R, Osman I, Alamah H, Zaied W, Haggag A. Sleep medicine knowledge among medical students in seven Egyptian medical faculties. J Sleep Disord Ther 2016;5:239

15 Zozula R, Bodow M, Yatcilla D, Cody R, Rosen RC. Development of a brief, self-administered instrument for assessing sleep knowledge in medical education: "the ASKME Survey." Sleep 2001;24(2):227-233

16 Balasubramaniam R, Pullinger A, Simmons M. Sleep medicine education at dental schools in Australian and New Zealand. J Dent Sleep Med 2014;1(1):9-16

17 Simmons MS, Pullinger A.Education in sleepdisordersinUSdental schools DDS programs. Sleep Breath 2012;16(2):383-392 